\title{
INVESTIGATION OF THE MECHANISM OF DUST FORMATION DURING TRANSPORTATION AND TRANSSHIPMENT OF RAW MATERIALS OF A CEMENT-MINING ENTERPRISE USING DISCRETE-ELEMENT MODELING
}

\author{
Sakhno S.
}

Kryvyi Rih National University, Ph. D., Assoc. Prof., Ukraine

\section{Korolyova J.}

Kryvyi Rig Cement PrJSC, Specialist of Heals and Safety, Ukraine

\section{Yanova $\mathbf{L}$.}

Kryvyi Rih National University, Ph. D., Assoc. Prof, Ukraine

\section{Pischikova 0.}

Kryvyi Rih National University, Ph. D., Assoc. Prof, Ukraine

\begin{abstract}
The subject of the study - investigation of dust formation processes in the zone of cement flour transfer from one conveyor to another.

Research methodology - the study of the behavior of particles of different dispersion during loading from one conveyor to another using the Discrete Element Method.

The goal - determination of places of localization of dust emission and the behavior of dust in these places to improve dust collection processes.

Conclusion of the study. The proposed method made it possible to identify the features of the interaction of particles of different dispersion both among themselves and with the surrounding space. The method designated areas where the most significant dust emission occurs and to which special attention should be paid when developing dust cleaning measures. The research results apply to various sectors of the mining and processing industries.
\end{abstract}

\section{Introduction}

Cement production is one of the most essential and most developing industries. In the technological process of cement production, raw materials used many bulk materials: limestone, clay, chamotte, sand, marl.

Cement production is associated with some environmentally harmful technological processes [1-3]. During the transportation of bulk materials by both conveyors and pneumatic transport, during 
their unloading, sorting, significant dust formation occurs. Dusting occurs when drying bulk materials, burning clinker in furnaces, crushing and grinding raw materials and clinker, packing in bags, and shipping to the consumer. As practice shows, a significant residual amount of dusty ingredients of a high degree of dispersion released into the atmosphere.

Reducing dust generation requires significant energy consumption. In this regard, it is crucial to determine localization sites and the mechanism of dust formation. This article discusses the features of dust formation during the overloading of raw flour from one conveyor to another.

\section{Object of study}

Three digital models have developed to study the dust emission processes occurring in the raw mix overload zone. Modeling performed in the Rocky Academic software system.

The first digital model made following the parameters of the zone of transfer of the raw mix from conveyor No. 74 to conveyor No. 49 of Kryvyi Rig Cement PrJSC and modeled the movement of particles when they fall. To save computing resources, this model considered the laminar motion of particles larger than $10 \mathrm{~mm}$ only.

The second digital model developed based on the first. However, it models the behavior of finely divided particles of raw mix with a size of less than $0.1 \mathrm{~mm}$.

The third digital model designed to study the behavior of fine particles of a raw mix in turbulent conditions.

Characteristics of materials and boundary conditions that accepted in the calculations shown in table 1.

Table 1

Characteristics of materials and boundary conditions for models 1-3

\begin{tabular}{|c|c|c|c|}
\hline Parameter & Value & Parameter & Value \\
\hline \multicolumn{2}{|c|}{ Raw mix } & \multicolumn{2}{|c|}{ Transfer hopper } \\
\hline Bulk Density & $1300 \mathrm{~kg} / \mathrm{m}^{3}$ & Density & $7850 \mathrm{~kg} / \mathrm{m}^{3}$ \\
\hline Young's Modulus & $1 \mathrm{e}+8 \mathrm{~N} / \mathrm{m}^{2}$ & Young's Modulus & $1 \mathrm{e}+11 \mathrm{~N} / \mathrm{m}^{2}$ \\
\hline Poisson's Ratio & 0,3 & Poisson's Ratio & 0,3 \\
\hline \multicolumn{2}{|c|}{ Air } & \multicolumn{2}{|c|}{ Belt } \\
\hline Velocity & $0 \mathrm{~m} / \mathrm{s}$ & Velocity & $2 \mathrm{~m} / \mathrm{s}$ \\
\hline Density & $1,617 \mathrm{~kg} / \mathrm{m}^{3}$ & Density & $1400 \mathrm{~kg} / \mathrm{m}^{3}$ \\
\hline Viscosity & $1,846 \mathrm{e}-5 \mathrm{~Pa} \quad \square \mathrm{s}$ & Young's Modulus & $1 \mathrm{e}+11 \mathrm{~N} / \mathrm{m}^{2}$ \\
\hline Temperature & $300^{\circ} \mathrm{K}$ & Poisson's Ratio & 0,3 \\
\hline
\end{tabular}


An analysis of the results obtained in the study of models will provide an understanding of the processes of dust emission in the feed flour overload zone, which can further used to select the optimal parameters of the dust collection system.

\section{Results of the research}

Digital model No. 1. This model (Fig. 1) designed to study the movement of particles of the raw mix when it falls from conveyor № 74 to conveyor № 49. The model made by the drawings of the Kryvyi Rig Cement PRJSC raw mix transfer zone and includes a feed and a receiving conveyor, as well as a loading conveyor bunker.

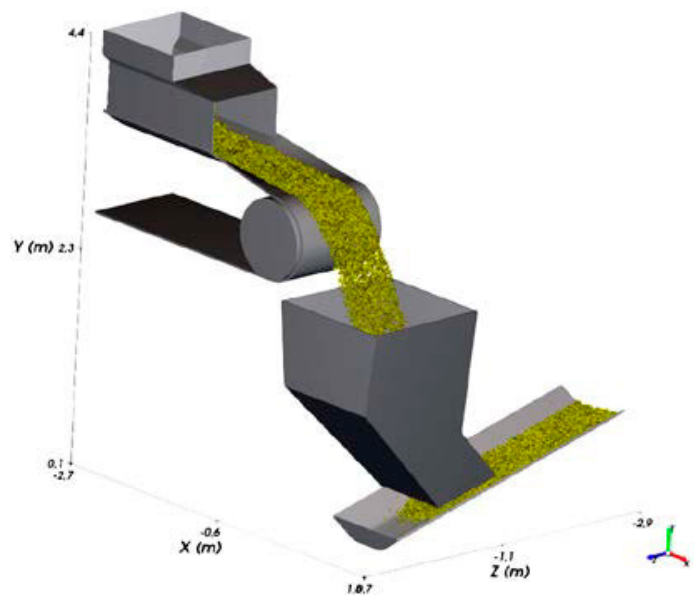

Fig. 1. General view of the digital Model № 1

A feed mix of $280 \mathrm{t} / \mathrm{h}$ supplied to feed conveyor № 74. The feed conveyor installed horizontally. Receiving conveyor № 49 in the horizontal plane is mounted perpendicular to the feeding conveyor, and in the vertical plane at an angle of $15^{\circ}$. The width of the conveyors is $1 \mathrm{~m}$.

To reduce the computational resource consumption in the model were considered only particles with a size of $10-40 \mathrm{~mm}$. In the calculation, particles in the form of a polyhedron with arbitrary orientation in space used. The particle size distribution showed in Figure 2. 


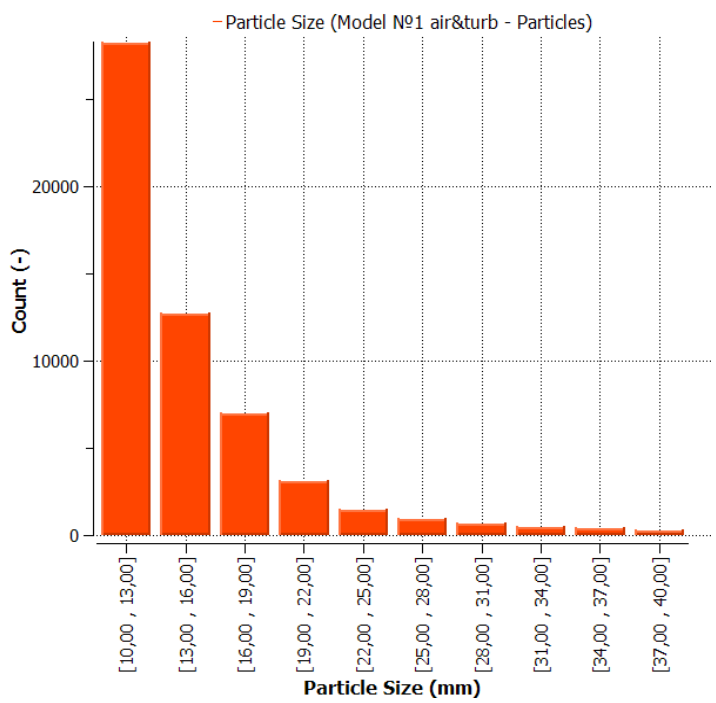

Fig. 2. The dispersed composition of particles in Model № 1

In the simulation, the interaction between particles and air taken into account. The simulation involved more than 55 thousand particles. In the research process, special attention paid to the trajectory of particle motion and the search for places of possible dust emission.

An analysis of the results showed that during the movement on the conveyor belt, the particle velocity is equal to the speed of the conveyor, and there is no mutual movement of particles. When falling from the feed conveyor until the moment of collision with the wall of the receiving hopper, the particles gain speed up to $7.6 \mathrm{~m} / \mathrm{s}$. After impact, the particles change the motion vector, and their speed depending on the place of contact with the walls of the reloading hopper is from 2 to $4 \mathrm{~m} / \mathrm{s}$ (Fig. 3). 


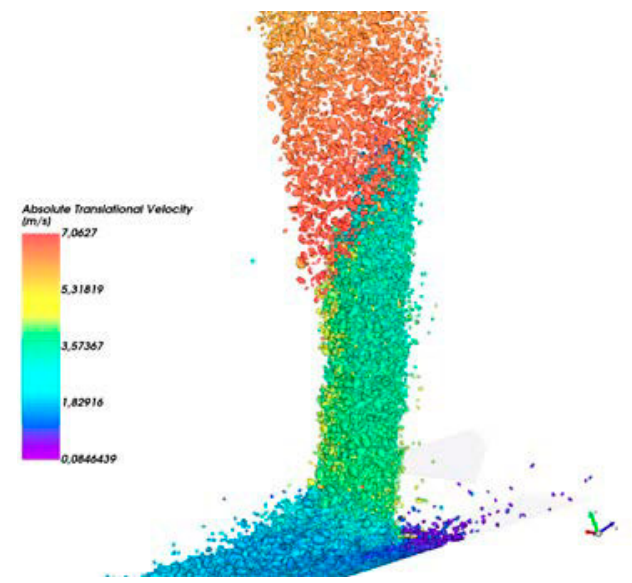

Fig. 3. The speed of movement of particles in the reloading hopper

After hitting the walls of the reloading hopper, the particles receive a rotational momentum. Moreover, as a rule, the smaller the particle size, the higher the rotational speed (Fig. 4).

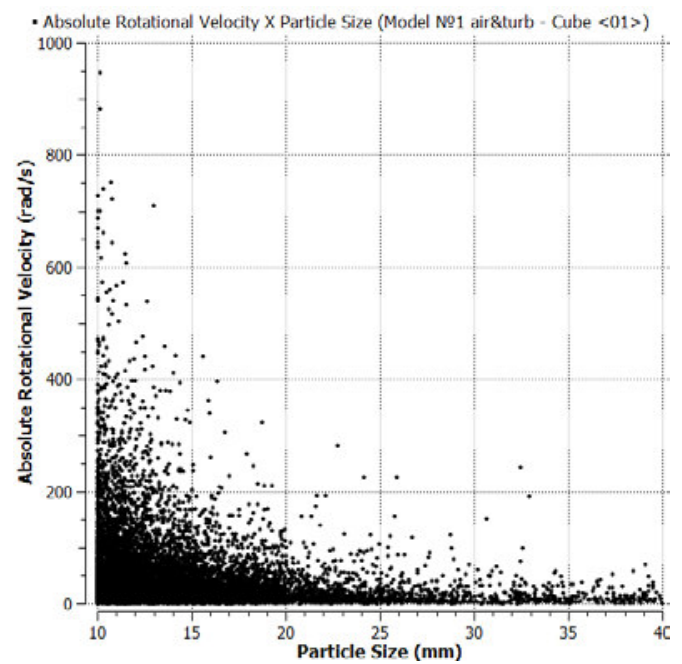

Fig. 4. Rotational speeds of particles in a reloading hopper

However, the number of revolutions of the particles is not significant (Fig. 5). In essence, $82 \%$ of the particles manage to make a max- 
imum of 4 revolutions. As a rule, the higher the rotational speed, the smaller the number of revolutions the particle has time to make (Fig. $6)$.

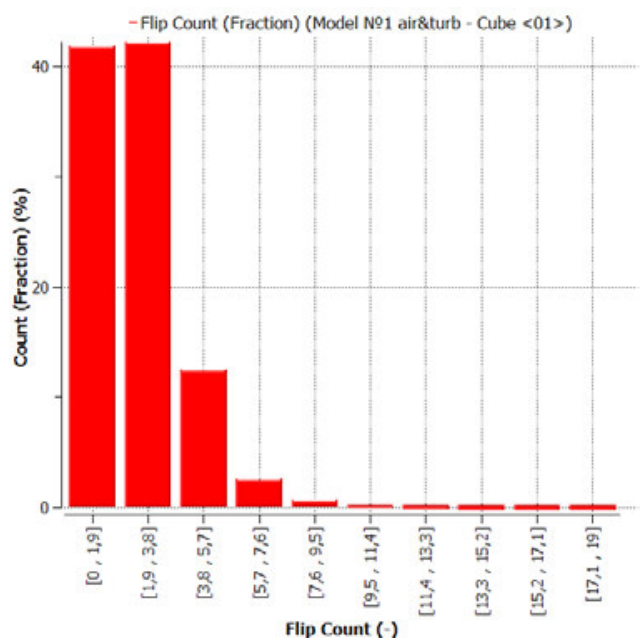

Fig. 5. The distribution of particles by the number of their rotations in the transfer hopper

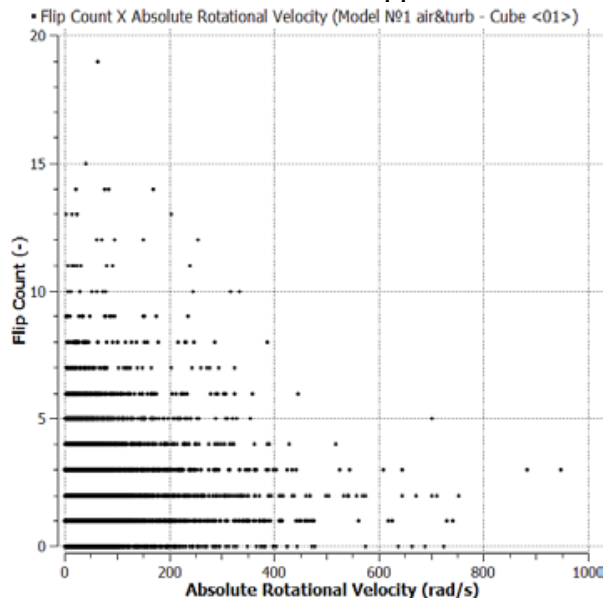

Fig. 6. The dependence of the number of rotations of particles on their angular velocity 
The most significant number of rotating particles observed in the zone of their contact with the transfer hopper walls and in the area of particle fall on the conveyor.

Model № 1 allowed us to study the number of interactions between particles over time (Fig. 7). There are two lines in fig. 7. The black line shows the change in the number of particles over time. The number of particles continuously increases until the raw mix reaches the end of the receiving conveyor, and the number of particles entering the model becomes equal to the number of particles dropped from the model.

The green line shows the change in the number of frictional contacts between particles over time. Until time point 1 , the particles move along the conveyor belt, and the number of contacts between them increases in proportion to the number of particles in the model. After time point 1 to point 2, there is a free fall of particles from the feed conveyor into the transfer hopper.

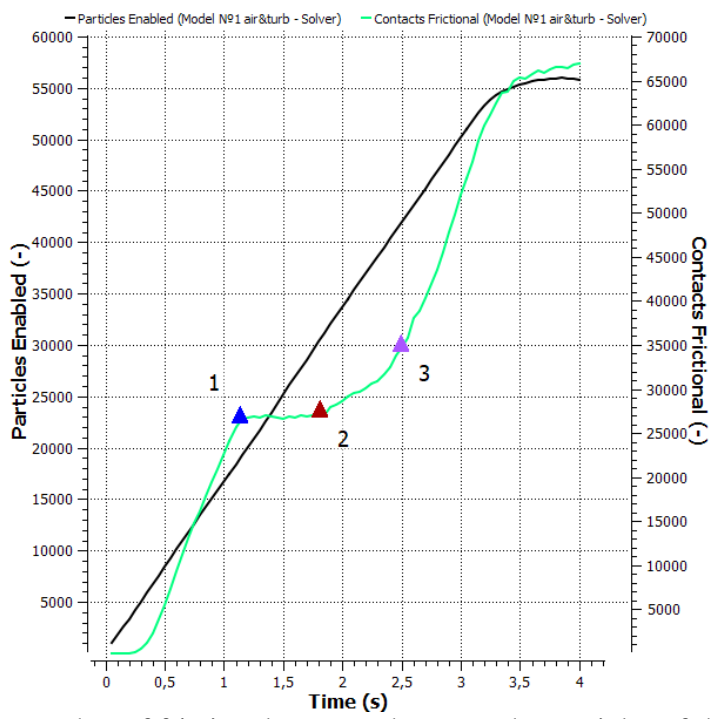

Fig. 7. The number of frictional contacts between the particles of the raw mix

During free fall, the particles practically do not touch each other; that is why line 1-2 is horizontal. In section 2-3, the particles interact with each other and with the walls of the transfer hopper, so the num- 
ber of contacts increases. After time point 3, particles fall on the receiving conveyor, the speed leveled, and the number of friction contacts again increases in proportion to the increase in the number of particles in the model.

Conclusions on model No 1. Given the data obtained, the following dust emission zones can be distinguished:

a zone of free fall of particles from the feed conveyor into the transfer hopper. Due to the significant difference in the velocities of small and large particles, the mixture flow is stratified, and air turbulence, which formed due to the movement of large particles, carries small particles in space. In more detail, this mechanism will be considered in the second and third models;

the zone of interaction of particles with the walls of the reloading hopper. In this zone, there is a sharp decrease in the speed of movement of particles while giving them a rotational impulse. As a result, air vortices formed and the number of shock interactions between particles increases, which provokes significant dust emission;

zone of falling particles from the reloading hopper to the receiving conveyor. The particle velocity in this zone is 2 to 3 times higher than the speed of the conveyor belt. As a result, shock interactions between particles and their rotation occur, which leads to significant dust emission.

Digital model № 2. This model developed based on the first, but it investigated the features of the motion of spherical particles. The movement of particles was considered only in the zone of their fall in the receiving hopper to reduce model resource consumption. The dispersed composition of particles shown in Fig. 8.

During the simulation, the behavior of more than 3.5 million particles investigated. In the simulation, the interaction between particles and air taken into account. During the analysis, special attention was paid to the vertical velocity of the movement of finely dispersed particles, taking into account air resistance. The turbulent particle motion was not taken into account in this model to reduce the calculation time. 


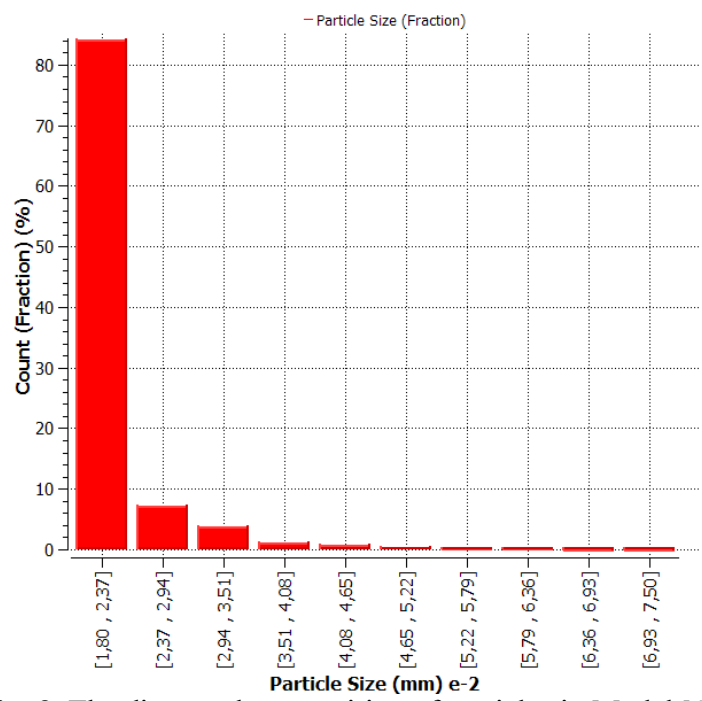

Fig. 8. The dispersed composition of particles in Model № 2

The behavior of the particles studied in the space in the center of the receiver limited by the size of $1 \times 0.6 \times 0.2 \mathrm{~m}$, Fig. 9 , to eliminate the influence on the speed of particles of the sidewalls of the receiver of raw flour.

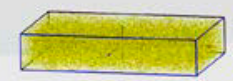

Fig. 9. Area of study of particle behavior

Because small particles reach the investigated space much later than larger ones, an analysis made of the velocity of the particles of 
the raw mix at different time intervals of the model. The results showed in Figure 10-11.

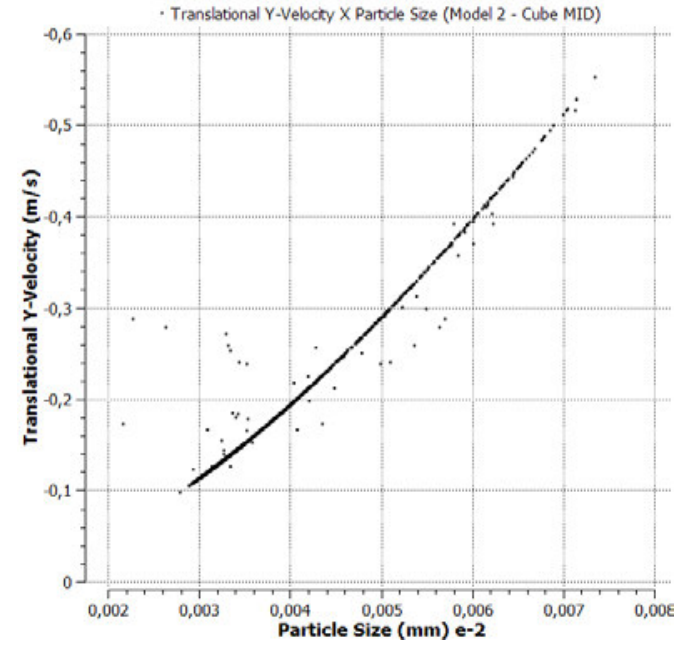

Fig. 10. Dependence of the rate of fall of particles on their size.3rd second of simulation

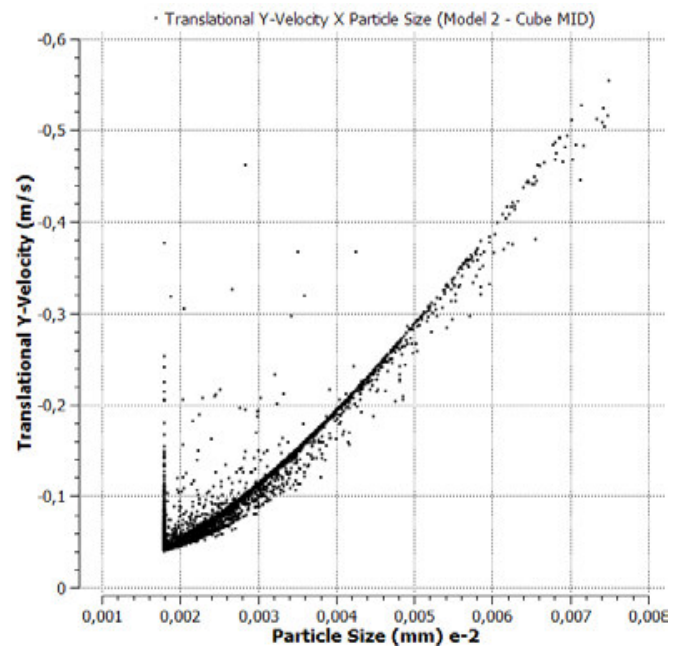

Fig. 11. Dependence of the rate of incidence of particles on their size. 16th second of simulation 
An analysis of the results shows that for the main bulk of the particles, the dependence of the rate of fall on their diameter is quadratic, which is consistent with the well-known calculation formula [4]

$$
V=d_{r}^{2} g \rho_{r} / 18 \mu
$$

where $V$ is the particle fall rate; $d_{r}$ is the particle diameter, $\mathrm{m} ; \mu$ dynamic viscosity, $\mathrm{Pa} \quad \rho_{r} \mathrm{~s} ;$ particle density, $\mathrm{kg} / \mathrm{m}^{3} ; g$ - gravity acceleration, $\mathrm{m} / \mathrm{s}^{2}$.

This dependence is especially noticeable in the graph of Fig. 10 formed under conditions when there was a small number of particles in the study zone. However, as the number of small particles increases in the 16th second of the simulation, the dependence becomes more blurred. For small particles, another line is clearly drawn, located slightly below the mainline, as well as a vertical line located in the zone of particles with the smallest diameter. Additional dependencies appear more clearly as the total number of particles of the raw mix increases (Fig. 11). The appearance of other dependences is associated with an increase in the number of frictional contacts between particles.

In some cases, larger particles carry smaller particles, which leads to a deviation of the velocity of small particles to higher values, in other cases, the collision of particles leads to a change in their motion vector, which reduces the vertical velocity component. Since this research model carried out without turbulence, the horizontal component of the velocity vector can arise only because of particle collisions. In Fig. 12 it is seen that the appearance of the horizontal velocity component more often occurs in small particles. Moreover, the lowest the particles, the higher the value of the horizontal component of the velocity vector.

Conclusions on model № 2. In general, the movement of fine particles without taking into account turbulence obeys known laws. However, with an increase in the density of particles in space, the particles begin to interact with each other.

The interaction or collision of particles occurs due to a significant, more than ten times, the difference in speeds of large and small particles. 


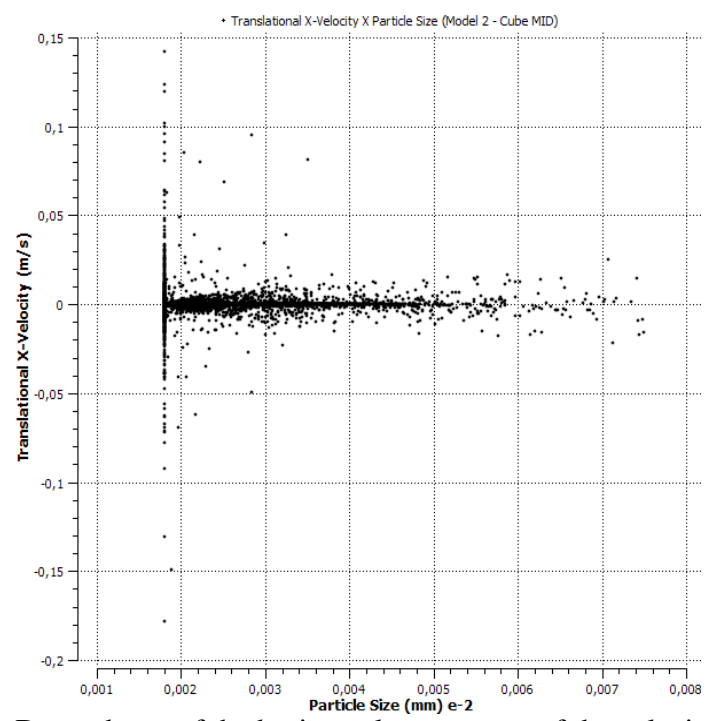

Fig. 12. Dependence of the horizontal component of the velocity vector on particle size

Because of the interaction, a horizontal component of the motion vector arises.

Moreover, the smaller the particles, the higher the frequency of occurrence of horizontal deviations, and the higher the value of the horizontal component of the velocity vector.

Digital Model № 3. This digital model includes a calculation area of $2 \times 2 \times 2 \mathrm{~m}$ in the upper part, of which there is a raw mix supply area (Fig. 13). The diameter of the feed area is $0.2 \mathrm{~m}$. The feed rate of the material is $8.7 \mathrm{t} / \mathrm{h}$.

During the simulation, the number of particles in the model initially increased and reached a maximum value of 130 thousand.

After three seconds, the material supply turned off, and in two seconds, the number of particles in the calculation space reduced to zero (Fig. 14).

In this model, the turbulence of particle motion taken into account during the simulation in contrast to the 1 st model. 


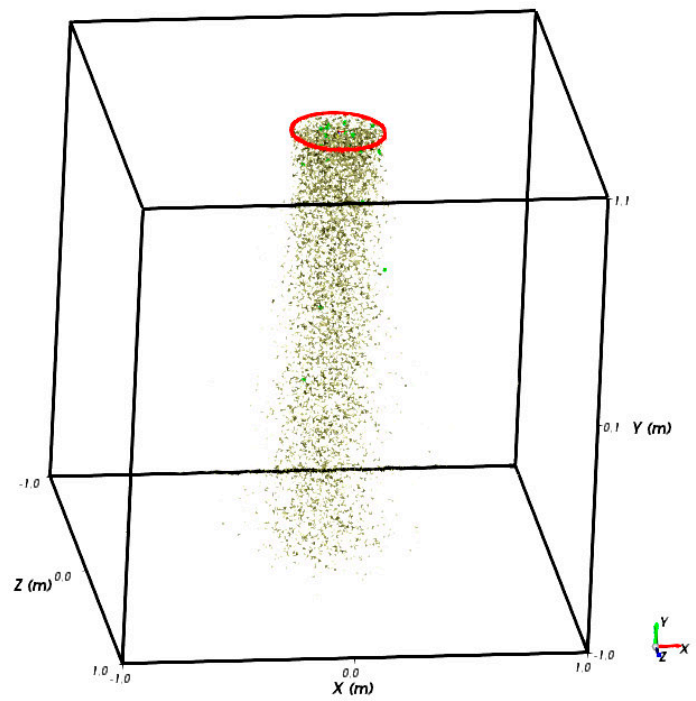

Fig. 13. Model № 3

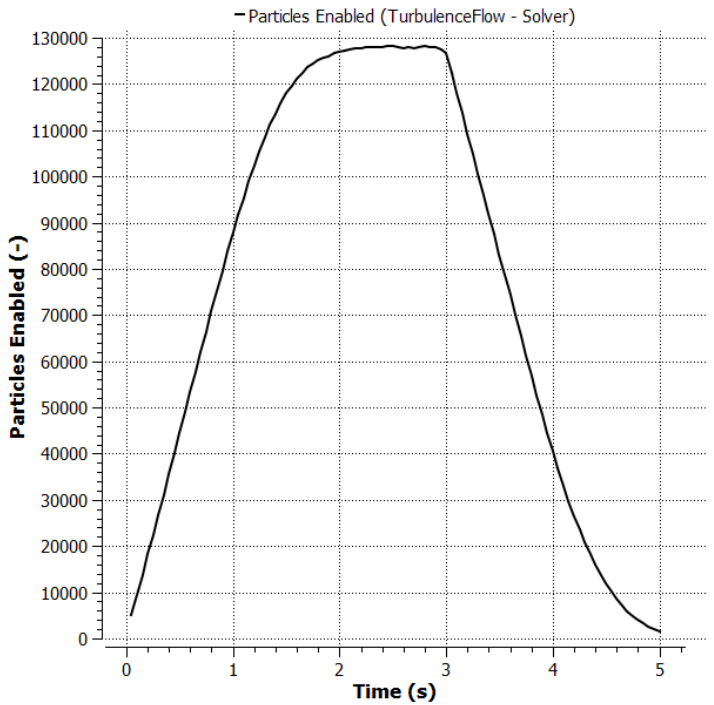

Fig. 14. The number of particles of raw flour that participated in the calculation of Model №3 
Special attention paid to the influence of turbulence and collisions on the deviation of the direction of motion of particles from vertical. Simulation results considered at four specific time points of these model:

0.25 seconds - the beginning of the loading of the particles of the raw mix. All fractions represent the composition of the mixture;

1.0 second - the fastest particles have reached the bottom of the computational domain, while the slowest are in the middle of the distance;

2.0 second - all particles reached the bottom of the computational domain. Since some of the larger and faster particles left the computational area, the fractional composition shifted toward smaller particles;

4.5 seconds - the feed mixture stopped 1.5 seconds ago. The upper part of the "dome" of particles is below the middle of the computational domain. Small particles predominantly represent the fractional composition.

The number of particles of various fractions in the computational space of the model at different periods shown in Fig. 15.

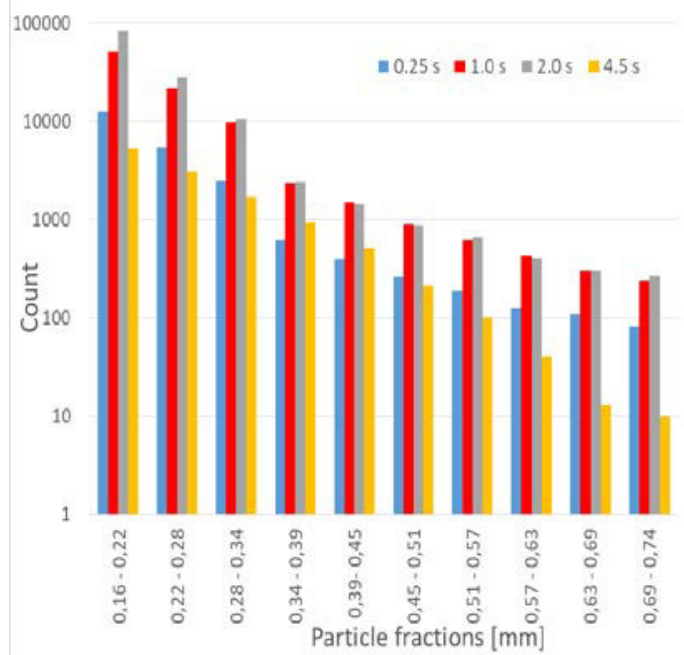

Fig. 15. The number of particles of various fractions in the computational space of Model № 3 at multiple points in time 
The changing in the average particle size of the model with time seen in Fig. 16.

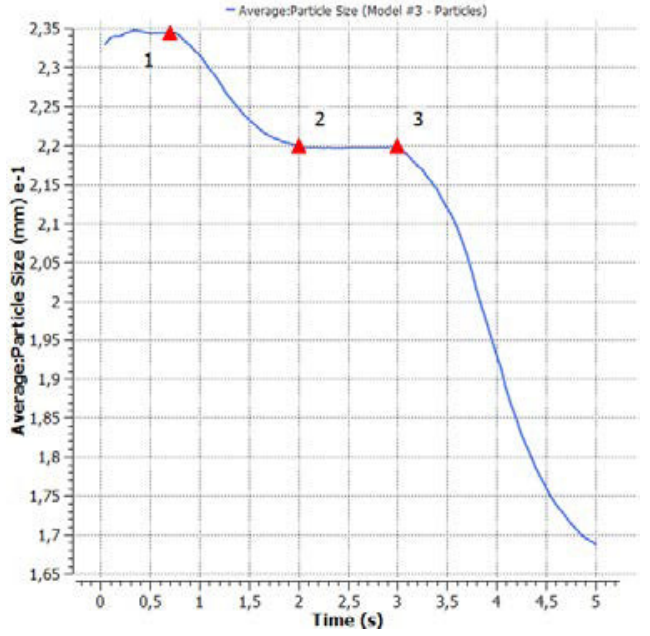

Fig. 16. Changing in the average particle size of the model over time

In fig. 16, point 1 corresponds to the achievement of large particles of the lower boundary of the calculation model, while increasingly smaller particles are still within the calculation zone. Position 2 corresponds to the moment when all particles have reached the lower boundary of the calculation zone, and the number of particles arriving in the model is equal to the number of decreasing ones. Point 3 corresponds to the moment the particle feed turned off. Due to the faster exit from the calculation zone of large particles, the average particle size is continuously decreasing.

An analysis of the results showed that deviations from the vertical direction of particle motion occur at all time stages of the simulation. At the initial points of the simulation, individual particles are characterized by high horizontal, up to $10 \mathrm{~m} / \mathrm{s}$, and even reverse vertical ascending velocities that quickly decay (Fig. 17). This phenomenon can be explained by tangential collisions of large particles with small ones and giving the latter a significant horizontal momentum. 


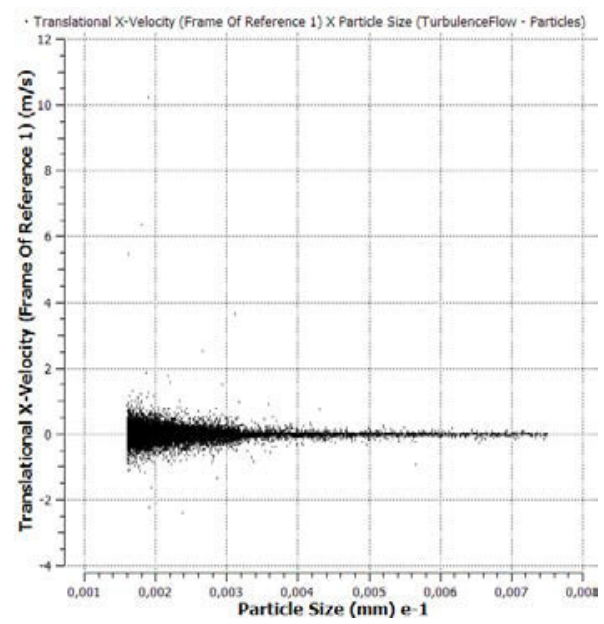

Fig. 17. Horizontal speeds of particles of various sizes at the time point of simulation $0.25 \mathrm{~s}$

Subsequently, with an increase in the number of particles, the quenching of high velocities of small particles occurs due to their mutual collision. At the same time, the overall speed spread increases due to the turbulent motion of particles, Fig. 18.

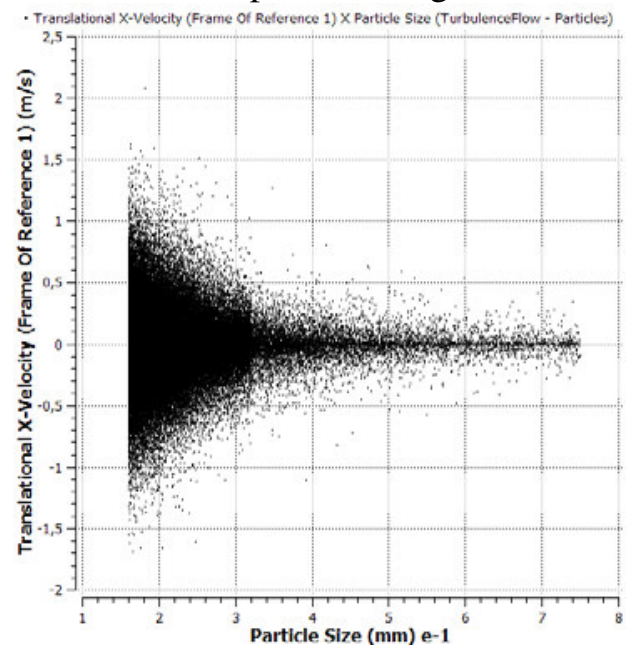

Fig. 18. Horizontal speeds of particles of various sizes at the time point of simulation $1.0 \mathrm{~s}$ 
The dispersion of horizontal velocities sharply increases for particles less than $0.3 \mathrm{~mm}$ in size. This is because, with a decrease in particle size, their number, and, correspondingly, the number of their interactions with each other increases.

Particles smaller than $0.3 \mathrm{~mm}$ are also characterized by a significant scatter in vertical velocity, Fig. 19. This confirms that particles smaller than $0.3 \mathrm{~mm}$ can have a significant mutual effect due to turbulent phenomena. Given the considerable velocity dispersion for particles $0-0.3 \mathrm{~mm}$ in size, substantial dust emissions should be expected for given particle size. An analysis was made of the distribution of particles in space to confirm this assumption.

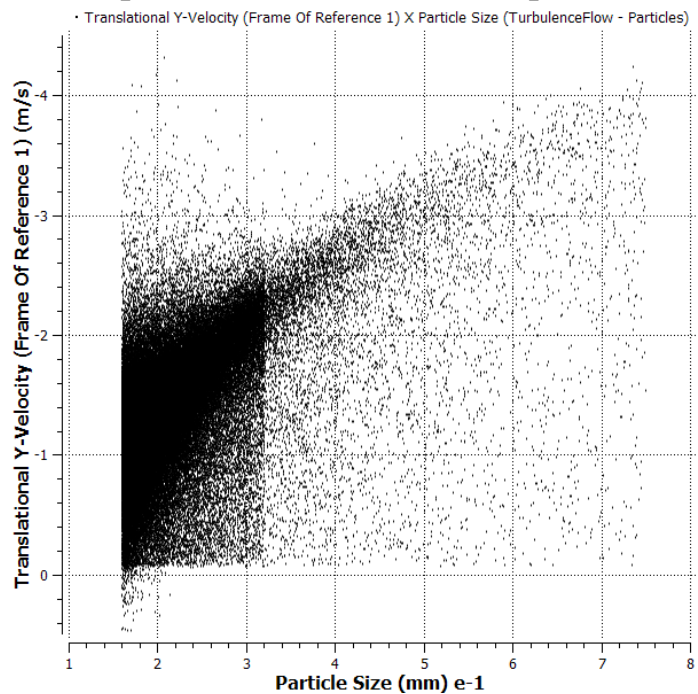

Fig. 19.The relationship of the vertical component of the particle velocity and particle size

Fig. 20 shows the dependence of the magnitude of the dispersion of particles on their size. As expected, the most significant scatter is characteristic of particles less than $0.3 \mathrm{~mm}$ in format.

The mass distribution of the raw mix over the scattering surface shown in Fig. 21. 


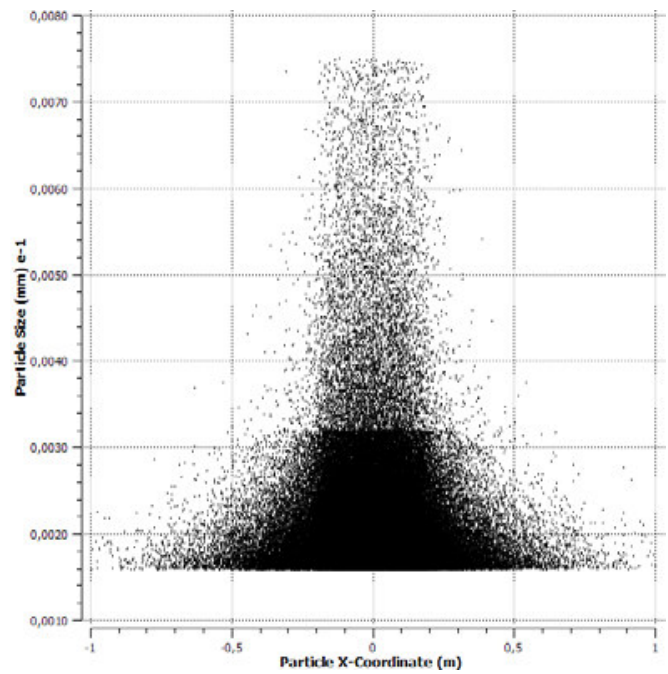

Fig. 20. Dependence of the size of the dispersion of particles on their size (time point $-3 \mathrm{~s}$ )

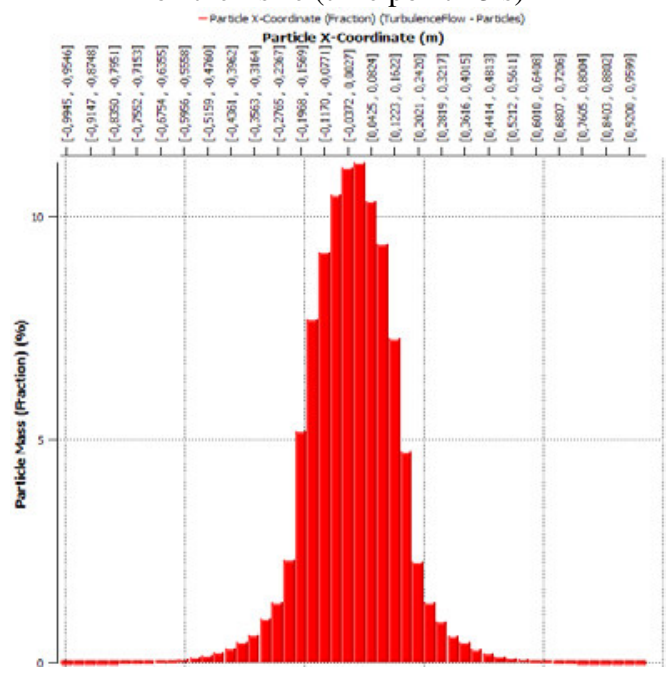

Fig. 21. The distribution of the mass of the raw mix on the surface of the spread

The histogram shows that outside the cylindrical region with a diameter of $0.2 \mathrm{~m}$ falls less than $5 \%$ of the mass of raw flour, and outside the area with a diameter of $0.3 \mathrm{~m}$ less than $2 \%$ of the weight of 
the raw mix. In this case, the original size of the particles extending beyond the region with a diameter of $0.3 \mathrm{~m}$ is less than $0.2 \mathrm{~m}$.

The Latis - Boltzmann method has used to check the impact of the particles on the air movement. The calculation results show that when moving, particles have a significant effect on the air. In the center of the particle flow, the air velocity reaches $1.4 \mathrm{~m} / \mathrm{s}$ with a particle velocity of $6.3 \mathrm{~m} / \mathrm{s}$ (Fig. 22). At a distance of $0.2 \mathrm{~m}$ outside the particle flow, the absolute air velocity is $0.4 \mathrm{~m} / \mathrm{s}$.

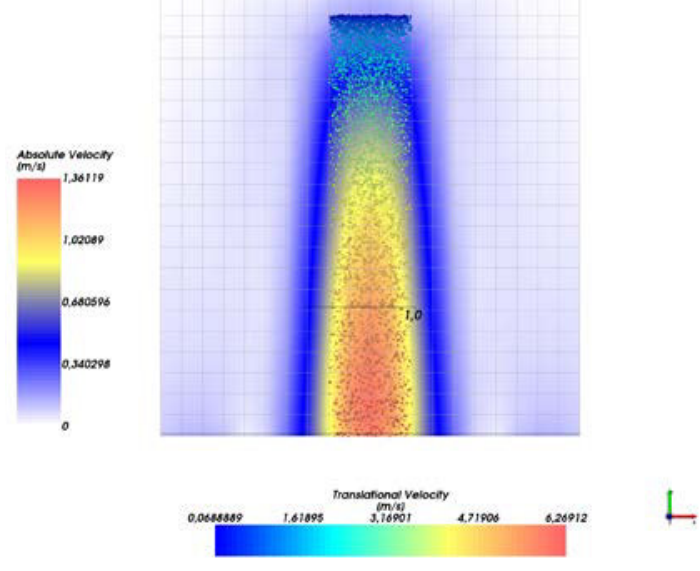

Fig. 22. Absolute speed of air. Vertical section

At the same time, a horizontal movement of air at a speed of about $0.1 \mathrm{~m} / \mathrm{s}$, directed inward to the particle stream, is observed near the flow of particles of the raw mix.

The direction of the air velocity vectors at different points of the model shown in Fig. 23.

The analysis results allow us to conclude that the stabilized particle flow is in an air cage. Outside the stream of particles, air tends to its surface.

At the same time, the horizontal component of the air velocity is comparable with the free-fall velocity of the small particles. This "drives" small particles into the stream.

A steady airflow inside the particle stream also entrains small particles and evens their speed with larger ones. 
Due to the considered phenomena, dust emission is minimal in the area of the steady flow of particles of the raw mix.

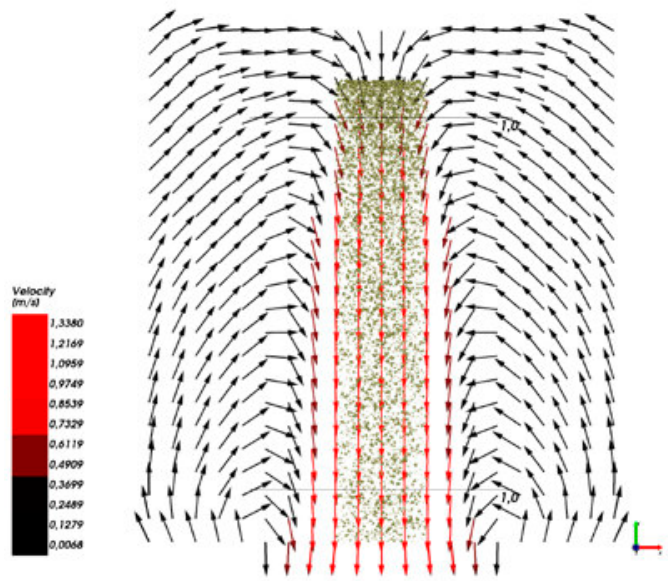

Fig. 23. The direction of the air velocity vectors along with the model

\section{Conclusions on the analysis of Model № 3}

When the particles of the raw mix move, they disperse in the horizontal plane. Dispersion occurs both due to the collision of particles with each other and due to turbulence.

Deviation from the vertical and the most significant variation in the velocity of motion is characteristic of particles with a diameter of less than $0.3 \mathrm{~mm}$. The most substantial deviation, and therefore the most significant role in dust formation, is played by particles with a size of less than $0.2 \mathrm{~mm}$.

For most particles less than $0.2 \mathrm{~mm}$ in size, the vertical velocity does not exceed $0.5 \mathrm{~m} / \mathrm{s}$.

The movement of particles of the raw mix causes a horizontal and vertical flow of air. The air velocity inside the particle stream reaches $1.4 \mathrm{~m} / \mathrm{s}$. Dust formation reduced due to the horizontal movement of air directed towards the center of the steady stream of particles.

\section{Conclusions}

In the process of overloading the raw mix from one conveyor to another, several zones of intense dust formation arise. The first is at 
the place of departure of the raw mix from the feed conveyor. The second is the place of interaction of the raw mix with the walls of the transfer hopper. The third is in the zone of particles entering the receiving conveyor.

The particles of the raw mix have significant differences in speeds in both vertical and horizontal directions. In the zone of interaction of particles with the reloading hopper walls, the rotational motion added to the translational movement of the particles. In this zone, the most intense dust generation occurs.

Particles of the raw mix during movement form air currents. Peculiarities of air movement help to reduce dust emission in stabilized vertical flows of the raw mix.

The highest dispersion and dust emission observed for particles less than $0.2 \mathrm{~mm}$ in size. Therefore, when choosing the parameters of dust cleaning devices, it is necessary to focus on the free fall rate of particles of this size.

References

1. Volkonskij, B.V., Lojko, L.M. (1971) Proizvodstvo cementa po suhomu sposobu [Cement production by dry method], Moscow: Izdatel'stvo literatury po stroitel'stvu.

2. Duda, V. (1981) Cement, Moscow: Strojizdat.

3. Azarov, V. N. (2004) Kompleksnaja ocenka pylevoj obstanovki i razrabotka mer po snizheniju zapylennosti vozdushnoj sredy promyshlennyh predprijatij [Comprehensive assessment of dusty conditions and measures to reduce the dust content of the working air area and environment of the industrial enterprises]: avtoref. dis. ... d-r tehn. nauk nauk: 05.26.01. Rostov-na-Donu.

4. Shapovalov V.A. (2001) Opredeleniye effektivnoy skorosti dlya transportirovki pyli po truboprovodam [Determining effective speed for conveying dust through pipelines]: Simpozium "Nedelya gornyaka" Moscow: MGGU. 